\title{
SHH Pathway and Cerebellar Development
}

\author{
Catherine Vaillant • Denis Monard
}

Published online: 18 February 2009

(C) Springer Science + Business Media, LLC 2009

\begin{abstract}
The morphogenetic factor Sonic hedgehog (SHH) has been discovered as one of the masterplayers in cerebellar patterning and was subjected to intensive investigation during the last decade. During early postnatal development, this continuously secreted cholesterolmodified protein drives the expansion of the largest neuronal population of the brain, the granular cells. Moreover, it acts on Bergmann glia differentiation and would potentially affect Purkinje cells homeostasis at adult age. The cerebellar cortex constituted an ideal developmental model to dissect out the upstream mechanisms and downstream targets of this complex pathway. Its deep understanding discloses some of the mechanistic disorders underlying pediatric tumorigenesis, congenital ataxia, and mental retardation. Therapeutical use of its regulators has been consolidated on murine transgenic models and is now considered as a realistic human clinical application. Here, we will review the most recent advances made in the comprehensive understanding of SHH involvement in cerebellar development and pathology.
\end{abstract}

Keywords Cerebellum · Development · Sonic hedgehog . Proliferation $\cdot$ Foliation

C. Vaillant

Developmental Genetics, Department Biomedicine,

University of Basel,

Mattenstrasse 28,

CH-4058 Basel, Switzerland

D. Monard $(\square)$

Friedrich Miescher Institut for Biomedical Research,

Maubeerstrasse 66,

CH-4058 Basel, Switzerland

e-mail: denis.monard@fmi.ch

\section{Overview}

The cerebellum has long been and remains an attractive model for neurobiologists. Its successive developmental steps gather the main cellular events leading to a highly organized architectural network, all orchestrated in a sequential and coordinated way that starts to be well defined. In particular, the involvement of the morphogenetic factor Sonic hedgehog (SHH) in the control of central nervous system progenitors proliferation was first demonstrated in this structure. This discovery has initiated an increasing number of studies underlying the crucial general role of this molecule in embryonic and adult brain patterning. SHH pathway is now on a therapeutical target at the crossroad of many developmental diseases, including some malignant tumors.

\section{The Hedgehog Pathway}

The hedgehog family, first identified in Drosophila embryonic development, is largely conserved in mammals and comprises three different proteins, Sonic hedgehog, Indian hedgehog, and Desert hedgehog. SHH was shown to play the broadest role in various organs including the nervous system during development $[1,2]$. The SHH pathway acts on gene expression through the activity of the GLI transcription factor family comprising GLI1, GLI2, and GLI3 (Fig. 1). In absence of SHH, its 12-pass transmembrane receptor Patched 1 (PTC) inhibits by default the seven-pass transmembrane protein $G$ coupled receptor Smoothened (SMO). This prevents the translocation of SMO to the primary cilia. Consequently, GLI3 becomes constitutively cleaved and converted into a transcriptional repressor form. Upon binding of SHH to PTC, the 
Fig. 1. $\mathrm{SHH}$ pathway. $\mathrm{SHH}$ ligand acts through the 12-pass transmembrane protein Patched (Ptc) and the seven-pass transmembrane protein smoothened $(\mathrm{Smo})$ to trigger an intracellular signal transduction pathway that results in the activation of the glioma-associated oncogene homologue (Glis) zinc finger transcription factors. In the absence of SHH, PTC blocks the function of SMO. Glis are inhibited by suppressor-of-fused (Sufu), preventing them from activating gene transcription. GLI3 is phosphorylated, recognized by $\beta-\operatorname{TrCP}$, and cleaved in the proteasome to produce truncated transcriptional repressor. The binding of SHH to PTC releases the basal repression on SMO that becomes active. Subsequently, GLI1 is released and activates gene transcription, whereas cleavage of GLI2 and GLI3 is blocked

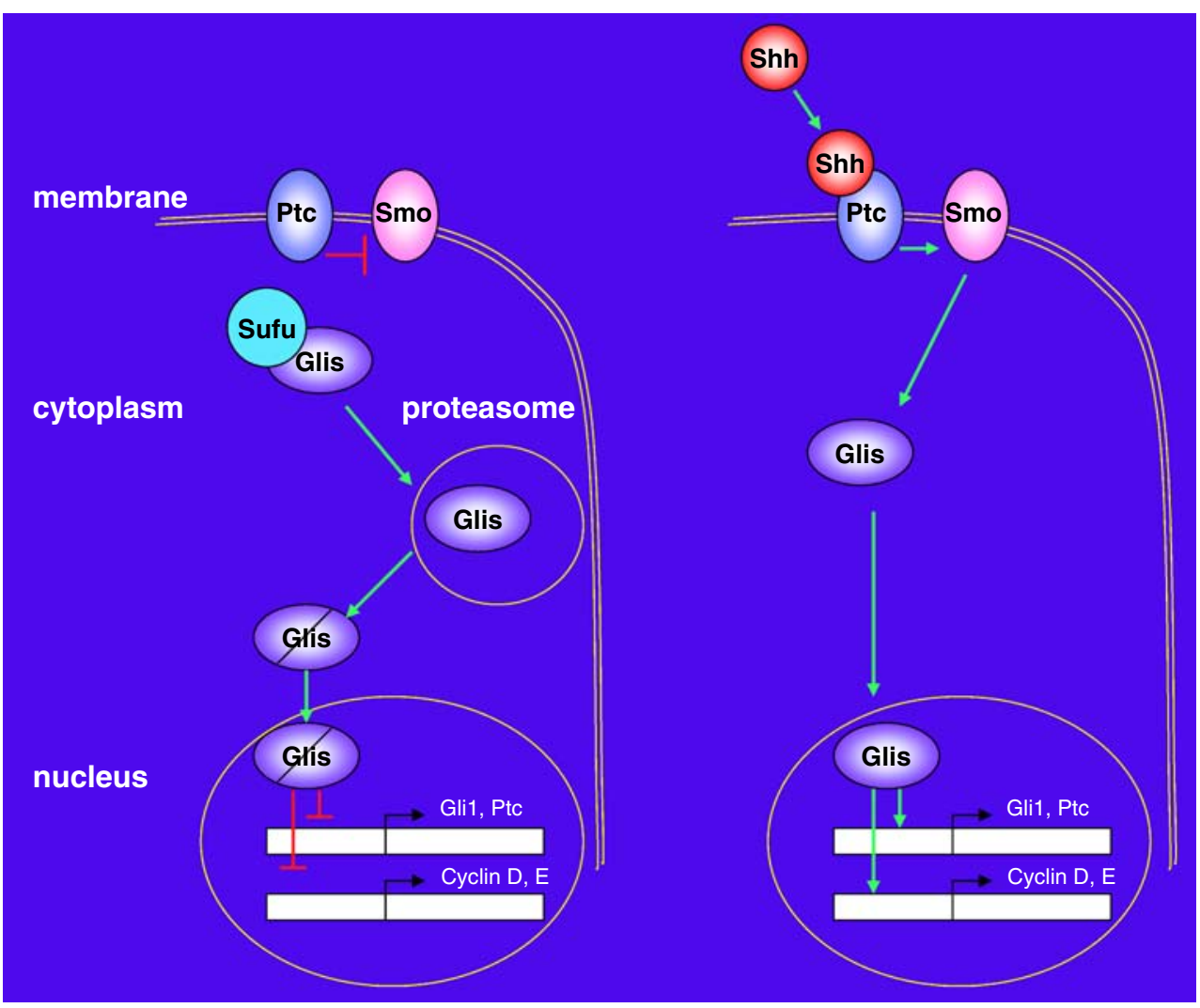

inhibition exerted on SMO is released, and this allows its accumulation in the cilia. SMO activates an inhibitory $G$ protein G $\alpha$ i that stops cAMP production [3]. The fulllength GLI3, no longer cleaved, becomes transcriptionally active together with GLI2, and both initiate a downstream activation of GLI1 [4, 5]. The target genes of the GLI factors are only partly identified. They belong to the cell cycle regulators and to the $\mathrm{SHH}$ pathway itself.

\section{Specific Role of SHH in the Developing Cerebellum}

The cerebellum is built up in successive waves of progenitors proliferation and migration throughout the embryonic and postnatal development. Most of the cerebellar cell types (Purkinje cells, Bergmann glia, astrocytes, interneurons, and neurons of the deep nuclei) arise from ventricular zone progenitors that migrate through the forming cortex during early embryogenesis. The cerebellar granular cells originate from a secondary germinal zone in the rostral rhombic lip [6]. These progenitors called cerebellar granular neuronal precursors (CGNPs) undergo a first wave of proliferation at E13,5 in the mouse. Then, from E17,5 on, they migrate over the nascent cerebellum to form the external granular layer (EGL), where their population massively expands. This proliferation phase peaks at P5-P8 and declines thereafter to stop at around P15 [7]. From about P8 on, CGNPs start extending processes and initiate their onwards migration. Their cell body closely apposed to the Bergmann glia fibers, they move through the growing network of the Purkinje cell dendrites in the molecular layer (ML) to reach the future internal granular layer (IGL). Their final neuronal differentiation is accomplished in the IGL about 3 weeks after birth.

The duration and intensity of the proliferation phase generating the pool of CGNPs is critical for the final shape and function of the cerebellum. SHH was discovered as the master player triggering the expansion of this population. Indeed, a putative involvement of $\mathrm{SHH}$ in cerebellum was first suspected from studies on the inhibition of cholesterol synthesis. As SHH needs to be cholesterol-modified to be active, this inhibition led to a defective $\mathrm{SHH}$ signaling causing abnormal cerebellar development [8-10]. In concordance, the human pathology Smith Lemli-Opitz syndrome, which is due to reduced cholesterol metabolism, is characterized by a hypoplastic cerebellum [11, 12].

The critical mitogenic function of $\mathrm{SHH}$ was evidenced almost simultaneously by four different groups [13-16]. From E17.5 on, SHH was shown to be continuously secreted from the Purkinje cells and to diffuse up to the EGL [13]. The outer EGL composed of proliferative CGNPs shows the highest expression of GLI1, read-out of the SHH pathway. These studies demonstrated the potent proliferative role of $\mathrm{SHH}$ on CGNPs using diverse combinations of in vitro and in vivo assays based on CGNPs cultures, slices, and/or explants and injection of 
inhibitory anti-SHH antibodies [13-15]. Among the already identified mitogens in the cerebellum (FGF-2, IGF-1, epidermal growth factor (EGF)), SHH turned out to clearly be the most potent mitogenic factor as it is solely able to trigger up to a 100 -fold increase of CGNP proliferation in vitro [15]. SHH proliferative effect on CGNPs is restricted to the sole postnatal phase, as its abrogation (using a SMOdeleted conditional knock-out (KO)) does not affect CGNPs expansion until soon after birth [17]. Gli2 transcriptional activation is critical for this expansion, as its conditional deletion leads to CGNP proliferation failure and reduced size of the cerebellum [18].

SHH signaling was also shown to affect the Bergmann glia population. These cells together with the CGNPs express high levels of Ptc and Gli1 [13, 19]. SHH addition to cultured cerebellar explants promotes Bergmann glia differentiation [13]. In addition, the fibers of the Bergmann glia are malformed and irregular upon conditional mutation of Gli2 [17]. The exact role of SHH in Bergmann glia maturation and function remains presently unclear. These observations, however, indicate that SHH does not only contribute to the final number of mature granular cells by promoting their initial expansion but also by inducing the maturation of their migration support.

SHH overall expression profile in early postnatal stages is directly responsible for the final size and shape of the cerebellum. Indeed, several groups reported an unequal distribution of the protein along the Purkinje cell layer, especially confined to the regions where fissures form first $[18,20]$. Finally, this was shown to determine the differential growth of the EGL ending in a defined size of folium. Absence of foliation was first demonstrated after conditional deletion of SHH or injection of blocking antiSHH antibodies [13, 20]. SHH-P1 mutants overexpressing SHH in the Purkinje cells presented with a larger cerebellum, and an extralobule could even be formed upon further increase of SHH activity in the SHH-P1; $\mathrm{Ptc}+/-$ mouse [17]. In conclusion, $\mathrm{SHH}$, although dispensable for determination of folium position, is required for full lobe extent.

\section{Effectors of the SHH Pathway}

SHH mediates CGNPs proliferation through the induction and repression of cell cycle regulators genes. Some studies attempted to have a comprehensive view of the genes affected during CGNPs proliferation, with or without addition of SHH [21, 22], and some promising candidates of the identified cascade have been tested for their impact. These include the cyclin family members, cyclin A2, B1, D1 and D2, the Forkhead transcription factor FoxM1, the growth factor IGF-2, the proto-concogene N- myc, and Bmi-1 $[16,23,24]$. In a feedback loop, SHH also triggers the transcription of Ptc and Gli1 and downregulates Gli3.

Cyclin D1 and D2 are known to regulate the G1/S phase transition. These are direct transcriptional targets of SHH, induced rapidly [16]. Absence of Cyclin D1 expression in the cerebellum decreases the number of cycling CGNPs [25]. In contrast to Cyclin D1, highly expressed in the EGL from E17 on, Cyclin D2 expression arises later in the outer EGL at around P6. Its deletion results in a mild hypoplastic cerebellum [26]. Altogether, deletion of both genes has a dramatic hypoplastic effect on the cerebellar development [27]. SHH modulates the G2/M transition through induction of the Forkheadd transcription factor FoxM1. It regulates mitotic entry through transcription of Cyclin B1 and $\mathrm{Cdc} 25 \mathrm{~b}$. Its deletion in CGNPs produces defects in spindle assembly and chromosome segregation [28].

Transcriptional induction by SHH requires the bHLH transcriptional activator N-Myc from the Myc/Max/Mad family $[16,22]$. N-myc and Mad form heterodimers with Max prior binding to DNA. In the cerebellum, N-Myc expression peaks in the proliferative CGNPs upon $\mathrm{SHH}$ stimulation. Conditional disruption of the $\mathrm{N}$-myc gene in the brain impairs CGNPs proliferation [29], and its overexpression is sufficient to boost CGNP proliferation [30]. Mad3, another bHLH transcription factor, was also identified as a target gene of SHH [31]. Expressed in CGNPs during their phase of expansion, it dimerizes with Max and recruits the corepressor Sin3 to inhibit DNA transcription. Mad3 overexpression is by itself sufficient to trigger CGNP proliferation [31].

The polycomb group gene Bmi-1 expression peaks in the CGNPs during their proliferation phase. Its deletion impairs their survival and expansion leading to a depleted IGL. Bmi-1 was demonstrated in culture as a downstream target and effector of SHH signal transduction [32].

\section{Regulators of the SHH Pathway}

It is, however, surprising that no decay of SHH expression is detected when the pool of CGNPs has been fully generated. The SHH level remains quite elevated even at mature adult stage [33]. The biological meaning of this high expression level has not been elucidated until now. As the modulation of SHH concentration strongly influences the final shape of the cerebellum [17], a tight regulation system seems required to control its biological impact. Some of the molecules involved in the tuning of the SHH mitogenic signal have been discovered, and their role, supportive or inhibitory, is partly understood. The mechanisms are extremely diversified and act at multiple levels. They can modulate the quantity of $\mathrm{SHH}$ protein by acting at the 
transcriptional level or interfere extracellularly or intracellularly with the SHH-dependent pathways (Fig. 2).

\section{Cooperative Regulators}

The positive regulators are synergistic to the mitogenic effect of SHH. This generally happens in the outer EGL to maintain a high number of continuously dividing CGNPs.

\section{Chemokines and Growth Factors}

The synergistic role of the chemoattractant SDF- $1 \alpha$ and of its receptor CXCR4 has been substantiated [34]. SDF- $1 \alpha$ has in fact a dual function: it attracts the CGNPs to the outer EGL and promotes in vitro a $50 \%$ increase of the SHH mitogenic effect. This synergy is effective through the CXCR4-mediated activation of the G-protein G $\alpha$ i, that would lead to a downstream decrease of cAMP [34].

Among fetal mitogens, IGF-2 has been reported as an efficient enhancer of SHH on CGNPs [35]. In cultured CGNPs, the presence of the recombinant IGF-2 further increases SHH stimulation by 2.2-fold [15]. The presence of IGF-2 significantly enhances Glil and cyclin D1 expression induced by SHH but not $N-m y c$ expression [35]. Altogether, the data clearly establishes IGF-2 as an important positive regulator of some SHH effects on CGNPs.

It has not yet been established which receptor (IGF-1R or IGF-2R) mediates the synergistic effect of IGF-2 on the SHH pathway. Whether IGF-1 can also potentiate SHH has not been determined either. IGF-2 synergistic effect would be mediated through the insulin receptor substrate 1 (IRS1) [36]. IGF-2 binding to IGF-1R leads to phosphorylation of IRS1 that finally activates the PI3K pathway. Knock-down experiments have shown that IRS1 activity is required for CGNP proliferation in slice explants and dissociated CGNPs cultures. IRS1 overexpression can maintain CGNP proliferation in the absence of SHH. SHH treatment upregulates IRS1 by stabilization of the protein rather than by transcription. Given the known proliferative effect of IGF1 on CGNPs and the fact that IRS1 is essential for IGFmediated proliferation in other cell types, these results identify IRS1 as a new effector of SHH in CGNP proliferation. They also provide evidence for interactions between SHH and other mitogenic pathways. In this respect, very recently published results showed experimental evidence for the first time of an interaction between the SHH and the mTOR pathways. mTOR, directly or indirectly through the phosphorylation of S6, stimulates the phosphorylation of IRS1 which leads to its degradation [37]. In cultured CGNPs, the inhibition of SHH signaling through cyclopamine decreases IRS1 protein levels. This effect is prevented by rapamycin, an inhibitor of the mTOR: Raptor complex[36]. However, the detailed mechanisms involved in this SHH-mediated mTOR inhibition will require further investigations.

\section{Extra Cellular Matrix}

The cellular environment, namely the extracellular matrix $(\mathrm{ECM})$, is intensively remodeled throughout cerebellar
Fig. 2. Schematic view of the developing cerebellar cortex including cooperative and negative regulators of SHH pathway. Postnatally, SHH is constantly secreted by the Purkinje cells and triggers CGNPs mitosis in the outer EGL, Bergmann glia differentiation, and possibly Purkinje cells maturation in the PCL. Its promitogenic effect on CGNPs is synergized by cooperative modulators (left) or tuned down by negative modulators (right). Signals can originate from different

compartments as specified. $E G L$ external granular layer, $I G L$ internal granular layer, $M L$ molecular layer, $P C L$ Purkinje cell layer

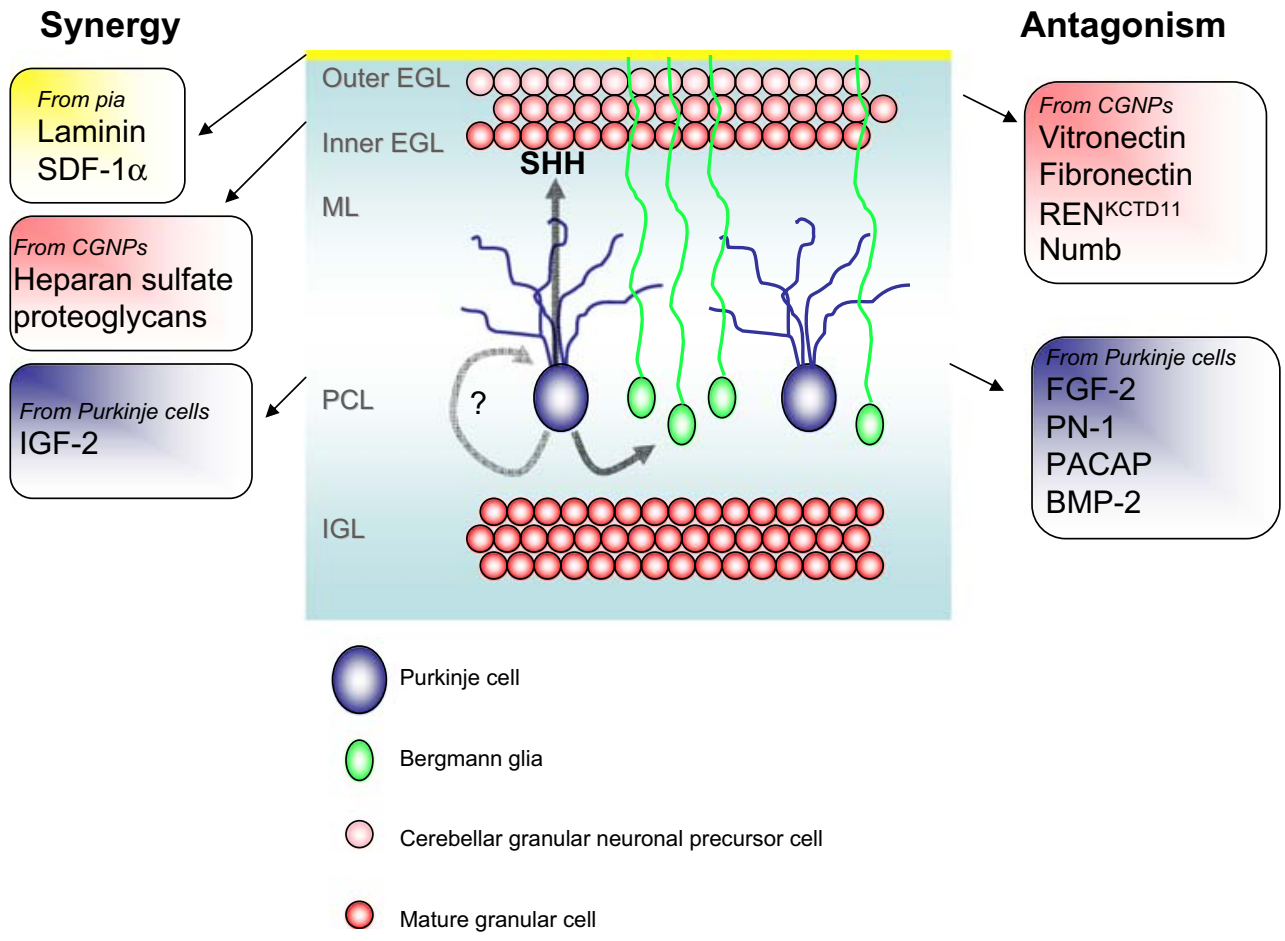


development. It provides distinct and changing cues for division or differentiation according to its content, which is often modified by the cell-derived proteolytic activity [38, 39]. The glycoprotein laminin originates from the cerebellar pial surface that immature CGNPs contact. In culture, it was shown that laminin activates CGNPs division rate by favoring the mitogenic potential of SHH [20, 34]. Laminin directly complexes with $\mathrm{SHH}$, and binding of the dimer to the receptor integrin $\beta 1$ subunit is critical for this synergystic effect [40]. Downstream, the cytoplasmic scaffold protein integrin linked kinase (ILK) is essential in the transduction of the proliferative signal. Its conditional deletion is reminiscent of the $\beta 1$ integrin conditional KO. Moreover, the blockade of its kinase activity suppresses SHH-mediated proliferation in cultured CGNPs. Its kinase domain would trigger downstream kinase candidates, such as GSK-3 $\beta$ and protein kinase B (PKB) [41].

In addition, the outer EGL is rich in heparan sulfate proteoglycans [42]. Treatment of organotypic cerebellar sections with heparinases abrogates SHH mitogenicity on CGNPs, suggesting a requirement for the proteoglycans, possibly in the promotion of protein interactions at the cell surface [42].

\section{Antagonistic Regulators}

On the other hand, the activity due to the persistent SHH high protein level must be tuned down by some negative regulators to favor CGNPs cell cycle exit and the onset of differentiation. Such antagonistic agents preferentially target the deep inner EGL.

\section{ECM and ECM Remodeling Agents}

Increasing levels of vitronectin and of its receptor, the integrin subunit $\alpha \mathrm{v}$, are found in the deep inner EGL. Vitronectin binds directly to $\mathrm{SHH}$ and has been shown to stop SHH-mediated mitosis by inducing the phosphorylation of cAMP response element-binding (CREB) [43], known to associate with Gli1 and the adaptor p300 to modulate SHH signaling. A similar inhibitory effect was observed for the ECM glycoprotein fibronectin [43].

The ECM fluctuates rapidly thanks to the involvement of proteases and their inhibitors. The serine-protease inhibitor Protease Nexin-1 (PN-1) is secreted by the Purkinje cell layer with a peak of expression during the proliferation temporal window. It was recently shown that its binding to the low density lipoprotein receptor-related protein (LRP) efficiently antagonizes SHH-induced mitosis in cultured CGNPs. Disruption of the PN-1 gene in vivo leads to overactivation of the SHH pathway and expansion of defined lobes [44]. The downstream mechanism has not yet been characterized but could rely on a competitive binding between PN-1, SHH, and the LRP receptor. Indeed, SHH binding to LRP and subsequent endocytosis has been evidenced using different cell lines [45]. Moreover, binding of SHH to LRP-2 has been established, and mice lacking LRP-2 (also named Megalin or gp330) exhibit numerous phenotypical similarities with the SHH-null mutant [46]. A role as coreceptor for LRP-2 or other LRPs in SHH signal transduction, similar to the function described for LRP-6 in Wnt pathway, still remains to be demonstrated. Furthermore, the binding of other LRP ligands could indirectly trigger a cross-reacting signaling cascade interfering with SHH pathway. For example, PN-1 binding to LRP-1 triggers protein kinase A (PKA) activation known to participate in GLI3 phosphorylation in fibroblasts and CGNPs ([47] and Vaillant, unpublished data).

\section{Growth Factors}

It is well established that increasing cAMP levels or protein kinase A activity stops SHH transduction [4]. The neuropeptide pituitary adenylate-cyclase activating polypeptide (PACAP) has been identified as one of the negative regulators of SHH pathway acting upstream of the PKA kinase [48]. Its binding to the G-coupled receptor PAC1 is considered to trigger an increase in cAMP leading to the final phosphorylation of the cAMP responsive transcription factor CREB. PACAP knock-out mice exhibit enlarged EGL coupled with overactivated SHH pathway [48].

Furthermore, SHH is inactivated by a growth-promoting mitogen, FGF-2. On its own, this growth factor stimulates CGNPs proliferation [15]. Intriguingly, its combination with SHH renders its proliferative effect unoperative and triggers CGNP differentiation $[15,49]$. The intraventricular injection of FGF-2 in vivo accelerates CGNP differentiation [49]. The mechanisms rely on the involvement of the mitogenactivating protein (MAP) kinase pathway. By the use of chemical inhibitors, the authors showed that fibroblast growth factor (FGF)-mediated antagonism requires FGF receptors and downstream activation of the extracellular regulated kinase (ERK) and junN-terminal kinase (JNK) kinases [49]. This impacts directly on the level of SHH target gene transcription. This discovery would explain the differential effect exerted by FGF and SHH on distinct cerebellar populations. Indeed, the same group reported the existence of multipotent neural stem cells dispersed in the white matter tracts of the developing and mature cerebellum. These cells, opposite to CGNPs, are positively stimulated for proliferation by FGF-2 but unaffected by SHH [50].

The cytokine BMP-2 antagonizes SHH-induced proliferation [51]. This mechanism is PKA-independent, and it is exerted by blocking N-Myc expression [52]. The BMP target gene TIEG-1 binds the Sp1 activator sites in the NMyc promoter. 
The novel EGF-responsive gene $\mathrm{REN}^{\mathrm{KCTD} 11}$, that has been discovered to be a prodifferentiating and growth arrest factor in the developing nervous system, accumulates in the postmitotic granular cells of the inner EGL [53]. In culture experiments, these authors demonstrate that ectopic expression of REN $^{\mathrm{KCTD} 11}$ leads to decayed proliferation in CGNPs, associated with a decreased activity of GLI1 and GLI2. Its loss of function supports SHH-dependant proliferation. $\mathrm{REN}^{\mathrm{KCTD} 11}$ would act by regulating the cyclindependent kinase inhibitor p27/Kip1 [54].

The developmental protein Numb also appears to be involved in SHH-mediated proliferation and signaling. This protein, critical for asymetric cell division, assigns cell polarity by accumulating in the newly generated daughter cells. Numb-deficient mice present with a cerebellar developmental phenotype marked by an enlarged EGL, where CGNPS are unable to start differentiation [55]. Di Marcotullio and collaborators [56] showed that Numb directly affects SHH signaling by promoting GLI1 degradation. Its effect first requires recruitment and complexation with the HECT-type E3 ligase Itch. This allows polyubiquitination of GLI1 that can no longer activate transcription in the nucleus [56].

\section{SHH in Disease}

\section{SHH and Medulloblastoma}

Deregulation of the SHH pathway is responsible for abnormal cerebellar proliferation, which results in one of the most common and most aggressive childhood brain tumors, medulloblastomas [57]. These highly malignant tumors belong to the subclass of primitive neuroectodermal tumors which account for about $20-30 \%$ of all childhood brain tumors [58]. A combination of surgery with radiation and chemotherapy represents the classical treatments, but the lack of accuracy often results in cognitive and neuroendocrine deficits, and tumors reoccur rather often.

Medulloblastomas have long been thought to arise from an exceeding proliferation of the CGNPs located in the EGL. However, some groups then reported expression in the tumors of markers typical from the remnant stem cells of the underlying IVth ventricle [59]. The medulloblastomas were also shown to contain multipotent neural stem cells that could be driven to the neuronal or glial lineage [60]. The identification of the "cell of origin" transformed by SHH oversignaling has been recently and simultaneously addressed by Yang et al. and Schüller et al. They have conditionally overactivated SHH pathway in lineagerestricted CGNPs and sought for their potential susceptibility to tumor formation $[61,62]$.
The first evidence of SHH involvement in medulloblastoma came from the characterization of the Gorlin syndrome, also known as basal cell nevus syndrome [63]. Gorlin patients carry germline mutations of the PTC receptor leading to its inactivation and subsequent $\mathrm{SHH}$ overactivation. Ten per cent of these patients develop medulloblastomas. Many reports described several other sporadic mutations affecting the SHH pathway, including, apart from PTC (in 10\% of the cases), SMO and the intracytoplasmic inhibitor of the SHH pathway suppressorof-fused (SUFU) [64-66]. The second evidence of the direct implication of SHH in medulloblastoma biology came from the murine experimental models. Targeted overexpression of SHH in neural progenitors of the cerebellum in newborn mice or in utero is sufficient to induce medulloblastoma [67, 68]. Moreover, inactivation of Ptc and constitutive activation of Smo in genetically engineered mice is sufficient to trigger tumor formation that faithfully recapitulates the biology of human tumors [65, 69-71]. The Ptc heterozygous mutant mice develop medulloblastomas (Fig. 3) with an incidence of about $20 \%$ within 1 year [69]. Gli1 is involved in the transformation as the double mutants Gli1 -/-, Ptc $+/-$ develop medulloblastomas at lower frequency than $\mathrm{Ptc}+/-$ mice [72]. The tumor frequency associated with the Ptc mutation increases dramatically in the p53 null background, exceeding $95 \%$ at 3 months of age [73]. Similarly Sufu ${ }^{+/} 53^{-/}$mice exhibit medulloblastomas, contrary to $\mathrm{Sufu}^{+/-}$mice that do not develop any tumor [74]. The tumor incidence seen in $\mathrm{Sufu}^{+/-} \mathrm{p} 53^{-/-}$mice reached $58 \%$ after 4 months of age and was then lower than the one seen in $\mathrm{Ptc}^{+/-} 53^{-/-}$mice, revealing that the Ptc gene is a more potent tumor suppressor.

Still, the incidence of these mutations is quite low in humans and does not account for the general SHH deregulation affecting most of the tumors, for more than $30 \%$ of them exhibit overexpression of the target gene Gli1 [75]. Given also the poor penetrance of tumor formation in the mouse models, such as the Ptc $+/-$ mutant, there must be additional causative factors at the origin of tumorigenesis. A growing number of reports identify some of these.

IGF-2 is often upregulated in the human medulloblastomas of the desmoplastic type [76]. Its requirement in SHHrelated oncogenesis was evidenced by the fact that its genetic deletion blocks medulloblastoma formation in the Ptc $+/-$ mutant mice [77]. IGF-2 binding to IGF-1R leads to final activation of PKB. Coexpression through retroviral injection of $\mathrm{Shh} / \mathrm{Igf}-2$ or $\mathrm{Shh} / P K B$ in neuronal progenitors drove increased formation of medulloblastomas with an efficiency of more than 2- and 3-fold, respectively, compared with SHH alone [78]. The PI3Kinase pathway was found to stabilize N-Myc through inhibition of its GSK-3 $\beta$-mediated phosphorylation [79]. Although retroviral coexpression of N-Myc and $\mathrm{SHH}$ in neural progenitors 
WT

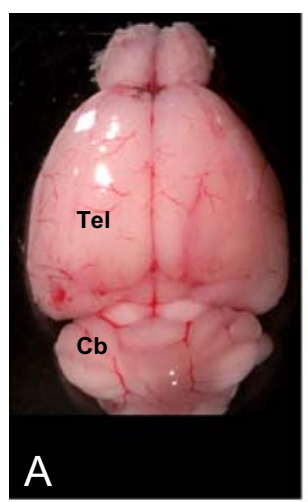

$\mathrm{Ptc}^{+/-}$
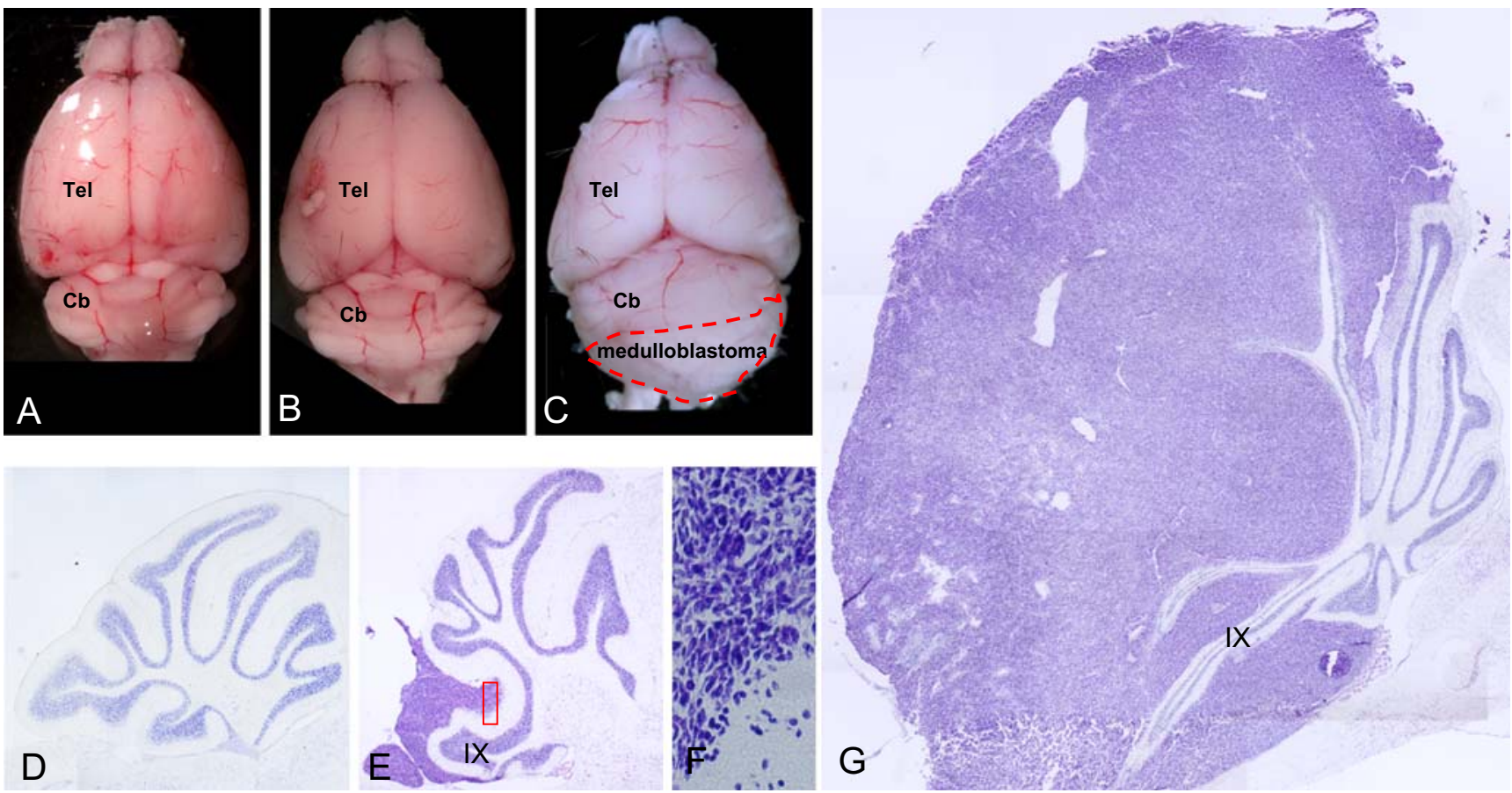

Fig. 3. Formation of medulloblastoma in the Ptc $+/-$ mouse. Sixmonth-old Ptc $+/-$ mice $(\mathbf{B}, \mathbf{C})$ exhibit bigger brain compared to wildtype (A). About $20 \%$ of them develop medulloblastoma (dotted in C). Ptc $+/-$ deprived of tumor (D). Tumors arise mainly in the lobe $I X-X$ (E). Their histology is characterized by dense and compacted

transformed granular progenitors (see enlargement of $\mathbf{E}$ in $\mathbf{F}$ ). Later, the tumors spread over the whole cerebellum at mature stages (G). Unpublished personal data. Similar data have been published earlier (Goodrich et al. [69]). $\mathrm{Cb}$ cerebellum, $\mathrm{Tel}$ telencephalon

reinforces medulloblastoma induction, N-myc ectopic expression, alone or combined with IGF pathway members or Gli1, produces no oncogenic effect [80]. This indicates that SHH needs additional unidentified factors to generate the tumor. In this respect, it is interesting to note that some of the molecules identified in association with medulloblastomas are among the effectors or cooperative regulators of the SHH pathway mentioned earlier.

A recent publication [81] strengthened the involvement of SHH pathway in medulloblastoma neoplasia. Over a group of 31 medulloblastomas biopsies, the authors identified a marked increase of GLI1 expression in half of them and split the group in high GLI1- and low GLI1-expressing tumor subsets. After a microRNA high-throughput expression profile analysis, they evidenced that the high GLI1 tumor subset showed a poor level of microRNAs targeting SMO and GLI1 3' UTRs. Interestingly, such miRNAs are transcribed in the chromosome $17 \mathrm{p}$ arm, a region frequently deleted in $40 \%$ of medulloblastomas. As medulloblastomas very rarely exhibit mutations of GLI1 or SMO, their overactivation could be attributed to mutation(s) resulting in repression of miRNA expression. These transcriptional regulators have also an inhibiting effect during normal postnatal development. Their ectopic expression reduces SHH-induced proliferation [81].

P53, HIC1, and $\mathrm{REN}^{\mathrm{KCD} 11}$, all known to cooperate normally with the SHH pathway, are affected as well by the $17 \mathrm{p}$ chromosom arm deletion commonly found in medulloblastomas. In mice, their deletion strengthens the effect of the Ptc heterozygous deletion [73, 82-84].

The comprehension and use of the physiological developmental SHH antagonists that have been or will be characterized will undoubtedly condition future therapeutical strategies (Table 1).

Several groups have undergone preclinical trial in this direction [85, 86-90]. The addition of FGF stops the growth of CGNPs extracted from a mouse model of medulloblastoma [49]. In addition, FGF stops the growth of human medulloblastoma cell lines [91] and human medulloblastoma xenografts injected in nude mice [92].

\section{SHH and Congenital Ataxia}

Primary cilia are determinant for SHH signal transduction. The SHH intramembranous transducer Smo concentrates in the cilia when activated by SHH, and PTC meanwhile leaves the cilia compartment [93]. In the cerebellum, disrupting primary cilia formation and maintenance by deleting Kif3a and IFT88 abolished SHH-mediated CGNPs proliferation [94, 95]. Interestingly, mutations of the genes 
Table 1 Possible therapeutic targets directly or indirectly affecting the SHH pathway in medulloblastomas

\begin{tabular}{|c|c|c|c|}
\hline Target & Strategy & Biological model & References \\
\hline \multirow[t]{2}{*}{ SMO } & Cyclopamine & $\begin{array}{l}\text { Primary cultures and allograft of medulloblastoma from } \mathrm{Ptc}+/-\mathrm{p} 53-/- \text { mice } \\
\text { Primary cultures of human medulloblastoma }\end{array}$ & Berman et al. $[85$ \\
\hline & $\begin{array}{l}\text { Small antagonist } \\
\text { HAntag }\end{array}$ & Oral administration in $\mathrm{Ptc}+/-\mathrm{p} 53-/-$ mice & Romer et al. [86] \\
\hline CXCR4 & AmD 3100 & Culture and xenograft of human medulloblastoma cell lines & $\begin{array}{l}\text { Rubin et al., } \\
\text { PNAS [87] }\end{array}$ \\
\hline \multirow[t]{4}{*}{ FGFR1-4 } & FGF-2 & Primary culture of CGNPs from mouse & Fogarty et al. [49] \\
\hline & FGF-2 & Primary culture of human classic medulloblastoma & Duplan et al. [91] \\
\hline & FGF-9 & & \\
\hline & FGF-2 & Xenograft of human medulloblastoma in nude mice & Vachon et al. [92 \\
\hline IGFR1 & $\begin{array}{l}\text { Anti-IGFR1 blocking } \\
\text { antibody }\end{array}$ & Murine medulloblastoma cell line & $\begin{array}{l}\text { Corcoran et al. } \\
\text { [88] }\end{array}$ \\
\hline IGF2 & Soluble IGF2 & Murine medulloblastoma cell line & $\begin{array}{l}\text { Corcoran et al. } \\
\text { [88] }\end{array}$ \\
\hline $\begin{array}{c}\text { Cholesterol } \\
\text { synthesis }\end{array}$ & $\begin{array}{l}\text { Sterol-synthesis } \\
\text { inhibitors }\end{array}$ & Medulloblastoma cell line of Ptc $+/-$ p53-/- mice & $\begin{array}{l}\text { Corcoran and } \\
\text { Scott [89] }\end{array}$ \\
\hline Math1 & $\begin{array}{l}\text { BMP-2, BMP-4, } \\
\text { BMP-7 }\end{array}$ & $\begin{array}{l}\text { Medulloblastoma cultures and allograft from } \mathrm{Cdkn} 2 \mathrm{c}^{-/-}, \operatorname{Trp} 53^{\mathrm{F} / \mathrm{Fl}}, \mathrm{Nes}^{-\mathrm{cre}^{+}} \text {, } \\
\text { and } \mathrm{Cdkn} 2 \mathrm{c}^{-/-}, \mathrm{Ptch}^{+/-} \text {mice }\end{array}$ & $\begin{array}{l}\text { Grimmer and } \\
\text { Weiss [90] }\end{array}$ \\
\hline
\end{tabular}

Experimental approaches on human or murine medulloblastomas have evidenced the potency of targeting SHH to reduce exceeding proliferation. The modulating properties of physiological SHH tuners come up as a promising tool

involved in the assembly and stability of cilia have been reported in the Joubert Syndrome [96]. This recessively hereditary disease is marked by a congenital ataxia and mental retardation linked to malformations of the brainstem, cerebellum, and cerebellar peduncles [97].

SHH is also suspected to play a role in a second congenital ataxia syndrome termed the Dandy-Walker malformation. In this case, chromosome regions encompassing Zic1 and Zic4 coding zones are deleted. Such Zinc finger transcription factors are thought to modulate SHH signaling pathway in the developing cerebellum [98], although the precise mechanisms of such regulation are still under investigation.

\section{SHH in Down Syndrome}

The Down Syndrome, also called trisomy 21, is marked by the inheritance of a supplementary chromosome 21 due to its improper disjunction during meiosis. Interestingly, Latash and Corcos [99] noted a reduction of the granular cell layer volume in the cerebellum of the patients with Down Syndrome accompanied by hypotonia and finemotor control impairment [99]. A mouse transgenic model of Down Syndrome Ts65Dn could phenocopy the reduction of CGNPs, resulting from an insufficient mitotic rate. In addition, the granular cells of the transgenic mouse exhibited reduced sensitivity to SHH $[100,101]$. Intraventricular infusion of recombinant SHH significantly rescued the reduced granular volume observed in the Ts65Dn.

\section{Conclusions}

In summary, the well-defined structure and developmental steps characterizing the cerebellum provided additional information and perspectives on the impact of SHH in the nervous system. In the future, it will be interesting to see whether studies in this structure will allow further important contributions. For example, the meaning of the persistent high expression of SHH in the adult cerebellum remains an intriguing issue. Is the biological activity of SHH strongly reduced or even masked by antagonists in the adult? Does discrete removal of such inhibition lead to localized impact of SHH in mature brain structures as observed in the adult rat nervous system [19]? Would such focalized activity influence the proliferation or fate of precursor cells as recently described in the mouse optic nerve [102]? Would it rather contribute to circuit, respectively synaptic plasticity by acting as axonal chemoattractant as shown in the midline axon guidance [103] or by enhancing retinoic acid induced neurite outgrowth as evidenced in a subpopulation of dorsal ganglia neurons [104]? Given the knowledge presently available, the cerebellum could be an appropriate in vivo model to better define distinct functions of SHH in the adult nervous system.

Acknowledgments Catherine Vaillant is supported by a research fellowship from the Swiss National foundation and Denis Monard by the Novartis Research Foundation. We would like to thank Dr Filippo Rijli for his critical reading of the manuscript. 


\section{References}

1. McMahon AP, Ingham PW, Tabin CJ (2003) Developmental roles and clinical significance of hedgehog signaling. Curr Top Dev Biol 53:1-114

2. Varjosalo M, Taipale J (2008) Hedgehog: functions and mechanisms. Genes Dev 22:2454-2472

3. DeCamp DL, Thompson TM, de Sauvage FJ, Lerner MR (2000) Smoothened activates Galphai-mediated signaling in frog melanophores. J Biol Chem 275:26322-26327

4. Huangfu D, Anderson KV (2006) Signaling from Smo to Ci/Gli: conservation and divergence of Hedgehog pathways from Drosophila to vertebrates. Development 133:3-14

5. Fuccillo M, Joyner AL, Fishell G (2006) Morphogen to mitogen: the multiple roles of hedgehog signalling in vertebrate neural development. Nat Rev Neurosci 7:772-783

6. Sillitoe RV, Joyner AL (2007) Morphology, molecular codes, and circuitry produce the three-dimensional complexity of the cerebellum. Annu Rev Cell Dev Biol 23:549-577

7. Hatten ME, Alder J, Zimmerman K, Heintz N (1997) Genes involved in cerebellar cell specification and differentiation. Curr Opin Neurobiol 7:40-47

8. Repetto M, Maziere JC, Citadelle D, Dupuis R, Meier M, Biade S et al (1990) Teratogenic effect of the cholesterol synthesis inhibitor AY 9944 on rat embryos in vitro. Teratology 42:611-618

9. Lanoue L, Dehart DB, Hinsdale ME, Maeda N, Tint GS, Sulik KK (1997) Limb, genital, CNS, and facial malformations result from gene/environment-induced cholesterol deficiency: further evidence for a link to sonic hedgehog. Am J Med Genet 73:24-31

10. Dehart DB, Lanoue L, Tint GS, Sulik KK (1997) Pathogenesis of malformations in a rodent model for Smith-Lemli-Opitz syndrome. Am J Med Genet 68:328-337

11. Yu H, Patel SB (2005) Recent insights into the Smith-LemliOpitz syndrome. Clin Genet 68:383-391

12. Porter FD (2003) Human malformation syndromes due to inborn errors of cholesterol synthesis. Curr Opin Pediatr 15:607-613

13. Dahmane N, Ruiz i Altaba A (1999) Sonic hedgehog regulates the growth and patterning of the cerebellum. Development 126:3089-3100

14. Wallace VA (1999) Purkinje-cell-derived Sonic hedgehog regulates granule neuron precursor cell proliferation in the developing mouse cerebellum. Curr Biol 9:445-448

15. Wechsler-Reya RJ, Scott MP (1999) Control of neuronal precursor proliferation in the cerebellum by Sonic Hedgehog. Neuron 22:103-114

16. Kenney AM, Rowitch DH (2000) Sonic hedgehog promotes G (1) cyclin expression and sustained cell cycle progression in mammalian neuronal precursors. Mol Cell Biol 20:9055-9067

17. Corrales JD, Blaess S, Mahoney EM, Joyner AL (2006) The level of sonic hedgehog signaling regulates the complexity of cerebellar foliation. Development 133:1811-1821

18. Corrales JD, Rocco GL, Blaess S, Guo Q, Joyner AL (2004) Spatial pattern of sonic hedgehog signaling through Gli genes during cerebellum development. Development 131:5581-5590

19. Traiffort E, Charytoniuk D, Watroba L, Faure H, Sales N, Ruat M (1999) Discrete localizations of hedgehog signalling components in the developing and adult rat nervous system. Eur J Neurosci 11:3199-31214

20. Lewis PM, Gritli-Linde A, Smeyne R, Kottmann A, McMahon AP (2004) Sonic hedgehog signaling is required for expansion of granule neuron precursors and patterning of the mouse cerebellum. Dev Biol 270:393-410

21. Diaz E, Ge Y, Yang YH, Loh KC, Serafini TA, Okazaki Y et al (2002) Molecular analysis of gene expression in the developing pontocerebellar projection system. Neuron 36:417-434
22. Oliver TG, Grasfeder LL, Carroll AL, Kaiser C, Gillingham CL, Lin SM et al (2003) Transcriptional profiling of the Sonic hedgehog response: a critical role for N-myc in proliferation of neuronal precursors. Proc Natl Acad Sci U S A 100:7331-7336

23. Sjostrom SK, Finn G, Hahn WC, Rowitch DH, Kenney AM (2005) The Cdk1 complex plays a prime role in regulating Nmyc phosphorylation and turnover in neural precursors. Dev Cell 9:327-338

24. Zhao Q, Kho A, Kenney AM, Yuk Di DI, Kohane I, Rowitch DH (2002) Identification of genes expressed with temporalspatial restriction to developing cerebellar neuron precursors by a functional genomic approach. Proc Natl Acad Sci U S A 99:5704-5709

25. Pogoriler J, Millen K, Utset M, Du W (2006) Loss of cyclin D1 impairs cerebellar development and suppresses medulloblastoma formation. Development 133:3929-3937

26. Huard JM, Forster CC, Carter ML, Sicinski P, Ross ME (1999) Cerebellar histogenesis is disturbed in mice lacking cyclin D2. Development 126:1927-1935

27. Ciemerych MA, Kenney AM, Sicinska E, Kalaszczynska I, Bronson RT, Rowitch DH et al (2002) Development of mice expressing a single D-type cyclin. Genes Dev 16:3277-3289

28. Schuller U, Zhao Q, Godinho SA, Heine VM, Medema RH, Pellman D et al (2007) Forkhead transcription factor FoxM1 regulates mitotic entry and prevents spindle defects in cerebellar granule neuron precursors. Mol Cell Biol 27:8259-8270

29. Knoepfler PS, Cheng PF, Eisenman RN (2002) N-myc is essential during neurogenesis for the rapid expansion of progenitor cell populations and the inhibition of neuronal differentiation. Genes Dev 16:2699-2712

30. Kenney AM, Cole MD, Rowitch DH (2003) Nmyc upregulation by sonic hedgehog signaling promotes proliferation in developing cerebellar granule neuron precursors. Development 130:1528

31. Yun JS, Rust JM, Ishimaru T, Diaz E (2007) A novel role of the Mad family member Mad3 in cerebellar granule neuron precursor proliferation. Mol Cell Biol 27:8178-8189

32. Leung C, Lingbeek M, Shakhova O, Liu J, Tanger E, Saremaslani P et al (2004) Bmil is essential for cerebellar development and is overexpressed in human medulloblastomas. Nature 428:337-341

33. Traiffort E, Charytoniuk DA, Faure H, Ruat M (1998) Regional distribution of Sonic Hedgehog, patched, and smoothened mRNA in the adult rat brain. J Neurochem 70:1327-1330

34. Klein RS, Rubin JB, Gibson HD, DeHaan EN, AlvarezHernandez X, Segal RA et al (2001) SDF-1 alpha induces chemotaxis and enhances Sonic hedgehog-induced proliferation of cerebellar granule cells. Development 128:1971-1981

35. Hartmann W, Koch A, Brune H, Waha A, Schuller U, Dani I et al (2005) Insulin-like growth factor II is involved in the proliferation control of medulloblastoma and its cerebellar precursor cells. Am J Pathol 166:1153-1162

36. Parathath SR, Mainwaring LA, Fernandez LA, Campbell DO, Kenney AM (2008) Insulin receptor substrate 1 is an effector of sonic hedgehog mitogenic signaling in cerebellar neural precursors. Development 135(19):3291-3300

37. Shah OJ, Hunter T (2006) Turnover of the active fraction of IRS1 involves raptor-mTOR- and S6K1-dependent serine phosphorylation in cell culture models of tuberous sclerosis. Mol Cell Biol 26:6425-6434

38. Vaillant C, Didier-Bazes M, Hutter A, Belin MF, Thomasset N (1999) Spatiotemporal expression patterns of metalloproteinases and their inhibitors in the postnatal developing rat cerebellum. J Neurosci 19:4994-5004

39. Vaillant C, Meissirel C, Mutin M, Belin MF, Lund LR, Thomasset N (2003) MMP-9 deficiency affects axonal out- 
growth, migration, and apoptosis in the developing cerebellum. Mol Cell Neurosci 24:395-408

40. Blaess S, Graus-Porta D, Belvindrah R, Radakovits R, Pons S, Littlewood-Evans A et al (2004) Beta1-integrins are critical for cerebellar granule cell precursor proliferation. J Neurosci 24:3402-3412

41. Mills J, Niewmierzycka A, Oloumi A, Rico B, St-Arnaud R, Mackenzie IR et al (2006) Critical role of integrin-linked kinase in granule cell precursor proliferation and cerebellar development. J Neurosci 26:830-840

42. Rubin JB, Choi Y, Segal RA (2002) Cerebellar proteoglycans regulate sonic hedgehog responses during development. Development 129:2223-2232

43. Pons S, Trejo JL, Martinez-Morales JR, Marti E (2001) Vitronectin regulates Sonic hedgehog activity during cerebellum development through CREB phosphorylation. Development 128:1481-1492

44. Vaillant C, Michos O, Orolicki S, Brellier F, Taieb S, Moreno E et al (2007) Protease nexin 1 and its receptor LRP modulate SHH signalling during cerebellar development. Development 134:1745-1754

45. McCarthy RA, Argraves WS (2003) Megalin and the neurodevelopmental biology of sonic hedgehog and retinol. J Cell Sci 116:955-960

46. Willnow TE, Hilpert J, Armstrong SA, Rohlmann A, Hammer RE, Burns DK et al (1996) Defective forebrain development in mice lacking gp330/megalin. Proc Natl Acad Sci U S A 93:8460-8464

47. Li X, Herz J, Monard D (2006) Activation of ERK signaling upon alternative protease nexin-1 internalization mediated by syndecan-1. J Cell Biochem 99:936-951

48. Nicot A, Lelievre V, Tam J, Waschek JA, DiCicco-Bloom E (2002) Pituitary adenylate cyclase-activating polypeptide and sonic hedgehog interact to control cerebellar granule precursor cell proliferation. J Neurosci 22:9244-9254

49. Fogarty MP, Emmenegger BA, Grasfeder LL, Oliver TG, Wechsler-Reya RJ (2007) Fibroblast growth factor blocks Sonic hedgehog signaling in neuronal precursors and tumor cells. Proc Natl Acad Sci U S A 104:2973-2978

50. Lee A, Kessler JD, Read TA, Kaiser C, Corbeil D, Huttner WB et al (2005) Isolation of neural stem cells from the postnatal cerebellum. Nat Neurosci 8:723-729

51. Rios I, Alvarez-Rodriguez R, Marti E, Pons S (2004) Bmp2 antagonizes sonic hedgehog-mediated proliferation of cerebellar granule neurones through Smad5 signalling. Development 131:3159-3168

52. Alvarez-Rodriguez R, Barzi M, Berenguer J, Pons S (2007) Bone morphogenetic protein 2 opposes Shh-mediated proliferation in cerebellar granule cells through a TIEG-1-based regulation of Nmyc. J Biol Chem 282:37170-37180

53. Gallo R, Zazzeroni F, Alesse E, Mincione C, Borello U, Buanne $P$ et al (2002) REN: a novel, developmentally regulated gene that promotes neural cell differentiation. J Cell Biol 158:731-740

54. Argenti B, Gallo R, Di Marcotullio L, Ferretti E, Napolitano M, Canterini $\mathrm{S}$ et al (2005) Hedgehog antagonist REN(KCTD11) regulates proliferation and apoptosis of developing granule cell progenitors. J Neurosci 25:8338-8346

55. Klein AL, Zilian O, Suter U, Taylor V (2004) Murine numb regulates granule cell maturation in the cerebellum. Dev Biol 266:161-177

56. Di Marcotullio L, Ferretti E, Greco A, De Smaele E, Po A, Sico MA et al (2006) Numb is a suppressor of Hedgehog signalling and targets Gli1 for Itch-dependent ubiquitination. Nat Cell Biol $8: 1415-1423$

57. Wetmore C (2003) Sonic hedgehog in normal and neoplastic proliferation: insight gained from human tumors and animal models. Curr Opin Genet Dev 13:34-42
58. Fogarty MP, Kessler JD, Wechsler-Reya RJ (2005) Morphing into cancer: the role of developmental signaling pathways in brain tumor formation. J Neurobiol 64:458-475

59. Eberhart CG (2007) In search of the medulloblast: neural stem cells and embryonal brain tumors. Neurosurg Clin N Am 18:59-69 viii-ix

60. Hemmati HD, Nakano I, Lazareff JA, Masterman-Smith M, Geschwind DH, Bronner-Fraser M et al (2003) Cancerous stem cells can arise from pediatric brain tumors. Proc Natl Acad Sci U S A 100:15178-15183

61. Schuller U, Heine VM, Mao J, Kho AT, Dillon AK, Han YG et al (2008) Acquisition of granule neuron precursor identity is a critical determinant of progenitor cell competence to form Shhinduced medulloblastoma. Cancer Cell 14:123-134

62. Yang ZJ, Ellis T, Markant SL, Read TA, Kessler JD, Bourboulas $M$ et al (2008) Medulloblastoma can be initiated by deletion of Patched in lineage-restricted progenitors or stem cells. Cancer Cell 14:135-145

63. Gorlin RJ (1995) Nevoid basal cell carcinoma syndrome. Dermatol Clin 13:113-125

64. Pietsch T, Koch A, Wiestler OD (1997) Molecular genetic studies in medulloblastomas: evidence for tumor suppressor genes at the chromosomal regions $1 \mathrm{q} 31-32$ and $17 \mathrm{p} 13$. Klin Padiatr 209:150-155

65. Taylor MD, Liu L, Raffel C, Hui CC, Mainprize TG, Zhang X et al (2002) Mutations in SUFU predispose to medulloblastoma. Nat Genet 31:306-310

66. Reifenberger J, Wolter M, Weber RG, Megahed M, Ruzicka T, Lichter $\mathrm{P}$ et al (1998) Missense mutations in $\mathrm{SMOH}$ in sporadic basal cell carcinomas of the skin and primitive neuroectodermal tumors of the central nervous system. Cancer Res 58:1798-1803

67. Weiner HL, Bakst R, Hurlbert MS, Ruggiero J, Ahn E, Lee WS et al (2002) Induction of medulloblastomas in mice by sonic hedgehog, independent of Gli1. Cancer Res 62:6385-6389

68. Rao G, Pedone CA, Coffin CM, Holland EC, Fults DW (2003) c-Myc enhances sonic hedgehog-induced medulloblastoma formation from nestin-expressing neural progenitors in mice. Neoplasia 5:198-204

69. Goodrich LV, Milenkovic L, Higgins KM, Scott MP (1997) Altered neural cell fates and medulloblastoma in mouse patched mutants. Science 277:1109-1113

70. Hallahan AR, Pritchard JI, Hansen S, Benson M, Stoeck J, Hatton BA et al (2004) The SmoA1 mouse model reveals that notch signaling is critical for the growth and survival of sonic hedgehog-induced medulloblastomas. Cancer Res 64:7794-7800

71. Mao J, Ligon KL, Rakhlin EY, Thayer SP, Bronson RT, Rowitch D et al (2006) A novel somatic mouse model to survey tumorigenic potential applied to the Hedgehog pathway. Cancer Res 66:10171-10178

72. Kimura H, Stephen D, Joyner A, Curran T (2005) Gli1 is important for medulloblastoma formation in Ptc1+/- mice. Oncogene 24:4026-4036

73. Wetmore C, Eberhart DE, Curran T (2001) Loss of p53 but not ARF accelerates medulloblastoma in mice heterozygous for patched. Cancer Res 61:513-516

74. Lee Y, Kawagoe R, Sasai K, Li Y, Russell HR, Curran T et al (2007) Loss of suppressor-of-fused function promotes tumorigenesis. Oncogene 26:6442-6447

75. Lee Y, Miller HL, Jensen P, Hernan R, Connelly M, Wetmore C et al (2003) A molecular fingerprint for medulloblastoma. Cancer Res 63:5428-5437

76. Pomeroy SL, Tamayo P, Gaasenbeek M, Sturla LM, Angelo M, McLaughlin ME et al (2002) Prediction of central nervous system embryonal tumour outcome based on gene expression. Nature 415:436-442

77. Hahn H, Wojnowski L, Specht K, Kappler R, Calzada-Wack J, Potter D et al (2000) Patched target Igf2 is indispensable for the 
formation of medulloblastoma and rhabdomyosarcoma. J Biol Chem 275:28341-28344

78. Rao G, Pedone CA, Del Valle L, Reiss K, Holland EC, Fults DW (2004) Sonic hedgehog and insulin-like growth factor signaling synergize to induce medulloblastoma formation from nestinexpressing neural progenitors in mice. Oncogene 23:6156-6162

79. Kenney AM, Widlund HR, Rowitch DH (2004) Hedgehog and PI-3 kinase signaling converge on Nmyc1 to promote cell cycle progression in cerebellar neuronal precursors. Development 131:217-228

80. Browd SR, Kenney AM, Gottfried ON, Yoon JW, Walterhouse D, Pedone CA et al (2006) N-myc can substitute for insulin-like growth factor signaling in a mouse model of sonic hedgehoginduced medulloblastoma. Cancer Res 66:2666-2672

81. Ferretti E, De Smaele E, Miele E, Laneve P, Po A, Pelloni M et al (2008) Concerted microRNA control of Hedgehog signalling in cerebellar neuronal progenitor and tumour cells. EMBO J 27:2616-2627

82. Di Marcotullio L, Ferretti E, De Smaele E, Argenti B, Mincione C, Zazzeroni $\mathrm{F}$ et al (2004) REN(KCTD11) is a suppressor of Hedgehog signaling and is deleted in human medulloblastoma. Proc Natl Acad Sci U S A 101:10833-10838

83. Ferretti E, De Smaele E, Di Marcotullio L, Screpanti I, Gulino A (2005) Hedgehog checkpoints in medulloblastoma: the chromosome 17p deletion paradigm. Trends Mol Med 11:537-545

84. Briggs KJ, Corcoran-Schwartz IM, Zhang W, Harcke T, Devereux WL, Baylin SB et al (2008) Cooperation between the Hic1 and Ptch1 tumor suppressors in medulloblastoma. Genes Dev 22:770-785

85. Berman DM, Karhadkar SS, Hallahan AR, Pritchard JI, Eberhart CG, Watkins DN et al (2002) Medulloblastoma growth inhibition by hedgehog pathway blockade. Science 297:1559-1561

86. Romer JT, Kimura H, Magdaleno S, Sasai K, Fuller C, Baines H et al (2004) Suppression of the Shh pathway using a small molecule inhibitor eliminates medulloblastoma in Ptc1(+/-)p53 (-/-) mice. Cancer Cell 6:229-240

87. Rubin JB, Kung AL, Klein RS, Chan JA, Sun Y, Schmidt K et al (2003) A small-molecule antagonist of CXCR4 inhibits intracranial growth of primary brain tumors. Proc Natl Acad Sci U S A 100:13513-13518

88. Corcoran RB, Bachar Raveh T, Barakat MT, Lee EY, Scott MP (2008) Insulin-like growth factor 2 is required for progression to advanced medulloblastoma in patched 1 heterozygous mice. Cancer Res 68:8788-8795

89. Corcoran RB, Scott MP (2006) Oxysterols stimulate Sonic hedgehog signal transduction and proliferation of medulloblastoma cells. Proc Natl Acad Sci U S A 103:8408-8413
90. Grimmer MR, Weiss WA (2008) BMPs oppose Math1 in cerebellar development and in medulloblastoma. Genes Dev 22:693-699

91. Duplan SM, Theoret Y, Kenigsberg RL (2002) Antitumor activity of fibroblast growth factors (FGFs) for medulloblastoma may correlate with FGF receptor expression and tumor variant. Clin Cancer Res 8:246-257

92. Vachon P, Girard C, Theoret Y (2004) Effects of basic fibroblastic growth factor on the growth of human medulloblastoma xenografts. J Neurooncol 67:139-146

93. Rohatgi R, Milenkovic L, Scott MP (2007) Patched1 regulates hedgehog signaling at the primary cilium. Science 317:372-376

94. Chizhikov VV, Davenport J, Zhang Q, Shih EK, Cabello OA, Fuchs JL et al (2007) Cilia proteins control cerebellar morphogenesis by promoting expansion of the granule progenitor pool. $\mathrm{J}$ Neurosci 27:9780-9789

95. Spassky N, Han YG, Aguilar A, Strehl L, Besse L, Laclef C et al (2008) Primary cilia are required for cerebellar development and Shh-dependent expansion of progenitor pool. Dev Biol 317:246-259

96. Millen KJ, Gleeson JG (2008) Cerebellar development and disease. Curr Opin Neurobiol 18:12-19

97. Louie CM, Gleeson JG (2005) Genetic basis of Joubert syndrome and related disorders of cerebellar development. Hum Mol Genet 14(Spec No. 2):R235-R242

98. Aruga J (2004) The role of Zic genes in neural development. Mol Cell Neurosci 26:205-221

99. Latash ML, Corcos DM (1991) Kinematic and electromyographic characteristics of single-joint movements of individuals with Down syndrome. Am J Ment Retard 96:189-201

100. Moldrich RX, Dauphinot L, Laffaire J, Rossier J, Potier MC (2007) Down syndrome gene dosage imbalance on cerebellum development. Prog Neurobiol 82:87-94

101. Roper RJ, Baxter LL, Saran NG, Klinedinst DK, Beachy PA, Reeves RH (2006) Defective cerebellar response to mitogenic Hedgehog signaling in Down [corrected] syndrome mice. Proc Natl Acad Sci U S A 103:1452-1456

102. Dakubo GD, Beug ST, Mazerolle CJ, Thurig S, Wang Y, Wallace VA (2008) Control of glial precursor cell development in the mouse optic nerve by sonic hedgehog from retinal ganglion cells. Brain Res 1228:27-42

103. Charron F, Stein E, Jeong J, McMahon AP, Tessier-Lavigne M (2003) The morphogen sonic hedgehog is an axonal chemoattractant that collaborates with netrin-1 in midline axon guidance. Cell 113:11-23

104. So PL, Yip PK, Bunting S, Wong LF, Mazarakis ND, Hall S et al (2006) Interactions between retinoic acid, nerve growth factor and sonic hedgehog signalling pathways in neurite outgrowth. Dev Biol 298:167-175 